\title{
PECULIARITIES OF BEAD SHAPE REGULATION IN SINGLE-LAYER MICROPLASMA SURFACING ON EDGES OF AIRCRAFT GAS TURBINE ENGINE BLADES*
}

\author{
P.D. ZHEMANYUK ${ }^{1}$, I.A. PETRIK ${ }^{1}$, S.L. CHIGILEJCHIK ${ }^{1}$, A.V. YAROVITSYN ${ }^{2}$ and G.D. KHRUSHCHOV ${ }^{2}$ \\ ${ }^{1}$ JSC «Motor Sich» \\ 15 Motorostroiteley Str., 69068, Zaporozhe, Ukraine. E-mail:motor@motorsich.com \\ ${ }^{2}$ E.O. Paton Electric Welding Institute, NASU \\ 11 Kazimir Malevich Str., 03680, Kiev, Ukraine. E-mail: office@paton.kiev.ua
}

\begin{abstract}
It is a necessary to specify the dependencies of deposited metal shaping due to the need of 5-15 mm height increase of the dimensions of surfacing-repaired damaged areas of blade edges of aircraft GTE of high-temperature nickel alloys in microplasma bead surfacing on narrow substrate of less than $3 \mathrm{~mm}$. A range of change of the process energy indices in «effective heat power of arc-heat input-cross-section area of deposited bead» system was investigated for conditions of corresponding single-layer surfacing, and effectiveness of process regulation of deposited layer cross-section was evaluated. It is determined that heat input change in 100-1600 J/mm range is the most effective regulation of cross-section area of the deposited bead under conditions of base metal limited penetration depth. It is assumed that the determined process relationship between heat input energy, height and cross-section area of the deposited bead will promote for formation of the additional criteria preventing crack formation in the «base-deposited metal» welded joint in repair of the parts of aircraft engines of high-temperature nickel alloys using multi-layer microplasma powder surfacing. 18 Ref., 4 Tables, 8 Figures.
\end{abstract}

Keywords : microplasma powder surfacing, high-temperature nickel alloy and heat-resistant cobalt alloy, narrow substrate, effective heat power of arc, heat input, thermal efficiency, cross-section area of deposited bead

One of the fields of application of arc surfacing on narrow substrate [1] of up to $3 \mathrm{~mm}$ width is the series repair of damaged or worn edges of aircraft gas turbine engine (GTE) blades [2-8]. The working blades of serially repaired aircraft engines D18T, D436, AI222, AI-450 are manufactured of nickel high-temperature alloys with polycrystalline structure (ZhS6U-VI, ZhS6K-VI) or of directionally-solidified alloys (ZhS32-VI and ZhS26-VI) [9]. These high-alloy materials, containing 55 and more vol.\% of $\gamma^{\prime}$-phase, are designed for operation at $1000-1100{ }^{\circ} \mathrm{C}$ temperatures and differ by high tendency to crack formation in fusion welding and/or further heat treatment [9, 10]. Argon-arc welding has been used for repair of such parts for more than 40 years, however, repair of the blade edges was limited by up to $2 \mathrm{~mm}$ depth and filler metal was inferior to base metal on heat resistance [2, 3].

Microplasma powder surfacing [4-8] has been successfully used for more than 10 years at JSC «Motor Sich» and SE «Ivchenko-Progress» for repair of aircraft working blades of given alloys with more than $3-5$ thou. h. running. Several grades of filler powders, in particular, high-temperature nickel alloy ZhS32 [4-8] and high-temperature cobalt and wear-resistant alloy V3K $[5,8]$, are widely used in this process.

Currently, serial repair production requires increase of dimensions of surfacing-repaired areas of blades (edges of platforms, labyrinth ends, Z-shape profiles and blade airfoil) to $5-15 \mathrm{~mm}$ height due to corresponding increase of size of wear zones, burnthrough and thermal fatigue cracks, developing in process of operation of these parts. Their restoration can be characterized as process of multi-layer surfacing, in which «base-deposited metal» welded joint can under certain conditions be susceptible to formation of micro- and macrocracks $[6,10,11]$. In turn, the multi-layer surfacing at some approximation can be presented as collection of single-layer beads. Therefore, it is relevant to expand the knowledges on the boundaries of energy indices range in single-layer surfacing for reasonable selection of such level and methods of balancing of heat input in the part, which provide for process strength of given welded joint, i.e. susceptibility of mentioned above materials to crack formation in fusion welding is not developed.

"Based on materials of paper, presented at the International Conference «Current welding technologies», July 11-13, 2016, Kiev, E.O. Paton Electric Welding Institute of the NAS of Ukraine. 


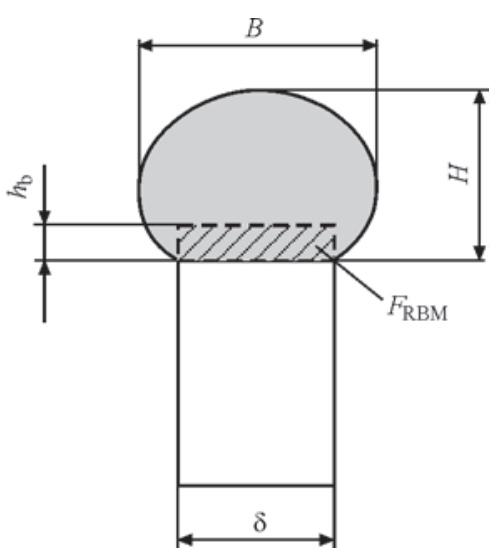

Figure 1. Scheme of measurement of deposited bead size: $\delta$ width of narrow substrate, $B$ - bead width; $H$ - bead height; $h_{\mathrm{b}}, F_{\mathrm{rbm}}$ - depth of penetration and cross-section area of remelted base metal

One of the constituents of this problem is detection of the dependencies and further optimizing the process regulation of shape of bead being deposited on narrow substrate. In addition to reasonable selection of volume of deposited metal in manual and automatic (robotic) surfacing, this allows also optimizing the dimensions of bead side reinforcement $p=0.5(B-\delta)$ in its cross-section (Figure 1).

In turn, side reinforcements of the deposited bead are the allowances being removed by mechanical treatment in formation of set geometry of the element repaired by surfacing. It is a danger of formation of burns and polishing cracks, therefore, abrasive treatment of the parts from high-temperature nickel alloys is carried out using special modes, equipment and abrasive disks $[12,13]$. At that, reduced rates of rotation of abrasive tool (to $25 \mathrm{~m} / \mathrm{s}$ ) and feed (350 $750 \mathrm{~mm} / \mathrm{min}$ ) are used for limiting removal intensity of the treated material [13]. Thus, mechanical treatment of the deposited metal, in spite of technical complexity of shaping of corresponding profile surfaces of the blade, is sufficiently laborious process, additionally requiring highly-qualified specialists, expensive equipment and materials. Therefore, reduction of width of the deposited bead promotes for significant extent decrease of laboriousness and increase of profitability of blade repair.

Aim of the present work lied in evaluation of the range of effective heat power of microplasma arc (previously was determined using flow calorimetry method [1] for corresponding value of welding current) and heat input for conditions of single-layer surfacing on narrow substrate of $\delta=0.3-3.0 \mathrm{~mm}$ width on modes close to optimum ones, and determination of basic dependencies of process regulation of shape of deposited bead cross-section.

Specimens from steel $12 \mathrm{Kh} 18 \mathrm{~N} 10 \mathrm{~T}$ of 90 $100 \times 30-40 \mathrm{~mm}$ size and $0.3-3.0 \mathrm{~mm}$ thickness were used as base metal. Surfacing on modes, described earlier in work [8], was carried out under conditions of free bead formation on the edge of plate being clamped in the jaws. The distance from deposited surface to copper jaws made not less than $20 \mathrm{~mm}$, and that from plasmatron outer exit to specimen was $5 \mathrm{~mm}$. The powders of ZhS32 and V3K alloys of 63-160 $\mu \mathrm{m}$ and 53-150 $\mathrm{m} \mu$ fraction, respectively, with different melting temperature (approximately by $70-90{ }^{\circ} \mathrm{C}$ ) and fluidity of weld pool molten metal were used as fillers. Argon of higher grade on GOST 10157-79 was applied as plasmaforming and transporting gas. The experiments were carried out at two types of equipment, different by type of disperse filler feed, level of constriction of microplasma arc and relative pulse duration of welding current $S$ :

- STARWELD 190H unit, plasmatron HPH80 (diameters of nozzle channels: plasma $d_{\mathrm{pl}}=2 \mathrm{~mm}$, focusing $d_{\mathrm{f}}=3 \mathrm{~mm}$ ), Kennametal Stellite $\mathrm{GmbH}$ company - continuous feed of powder (consumption of transporting gas $Q_{\mathrm{tr}}=31 / \mathrm{min}, S \approx 1.5$;

- UPNS304M2/M3 unit, plasmatron PPS04 $\left(d_{\mathrm{pl}}=2.5 \mathrm{~mm}, d_{\mathrm{f}}=4.5 \mathrm{~mm}\right)$ - dosed feed of powder $\left(Q_{\mathrm{tr}}=21 / \mathrm{min}\right), S \approx 4.5$.

Processing of experimental data was carried out using the regression dependencies of value of efficient heat power of microplasma arc $q_{\mathrm{u}}$ from welding current $I$, received earlier using the flow calorimetry method [1]. Heat input $q_{\mathrm{u}} / v$ was determined by procedure of work [11]:

$$
q_{\mathrm{u}} / v=Q_{\Sigma} / L,
$$

where $Q_{\Sigma}$ is the heat input in the anode taking into account effective efficiency of part heating $[1,11] ; L$ is the given length of elliptic bead cylinder. Cross-section areas of the deposited bead $F_{\mathrm{b}}$ and deposited metal in it $F_{\mathrm{db}}=F_{\mathrm{b}}-F_{\mathrm{rbm}}$ were determined using calculation by procedure of work [14] based on measurement of width, height of bead and base metal penetration depth with up to $0.05 \mathrm{~mm}$ accuracy, according to Figure 1. Thermal efficiency for $\mathrm{ZhS} 32$ deposited metal was determined by calculation [11] proceeding from its cross-section area $F_{\mathrm{db}}$ :

$$
\eta_{\mathrm{th}}=\frac{M_{\mathrm{s}} H_{\mathrm{m}}}{q_{\mathrm{u}}},
$$

where $H_{\mathrm{m}}=861.2$ and $1312.6 \mathrm{~J}$ is the specific enthalpy of $1 \mathrm{~g}$ of deposited metal ZhS32 and base metal 12Kh18N10T, respectively.

Firstly, the dependencies of change of the energy indices of process of microplasma powder surfacing and indices of bead shape for narrow substrate $\delta=$ $=0.3-2.0 \mathrm{~mm}$ (Figure 2 and Table 1) were evaluated. It is determined that the effective heat power of the microplasma arc varies in 30-330 $\mathrm{W}$ range, heat in- 

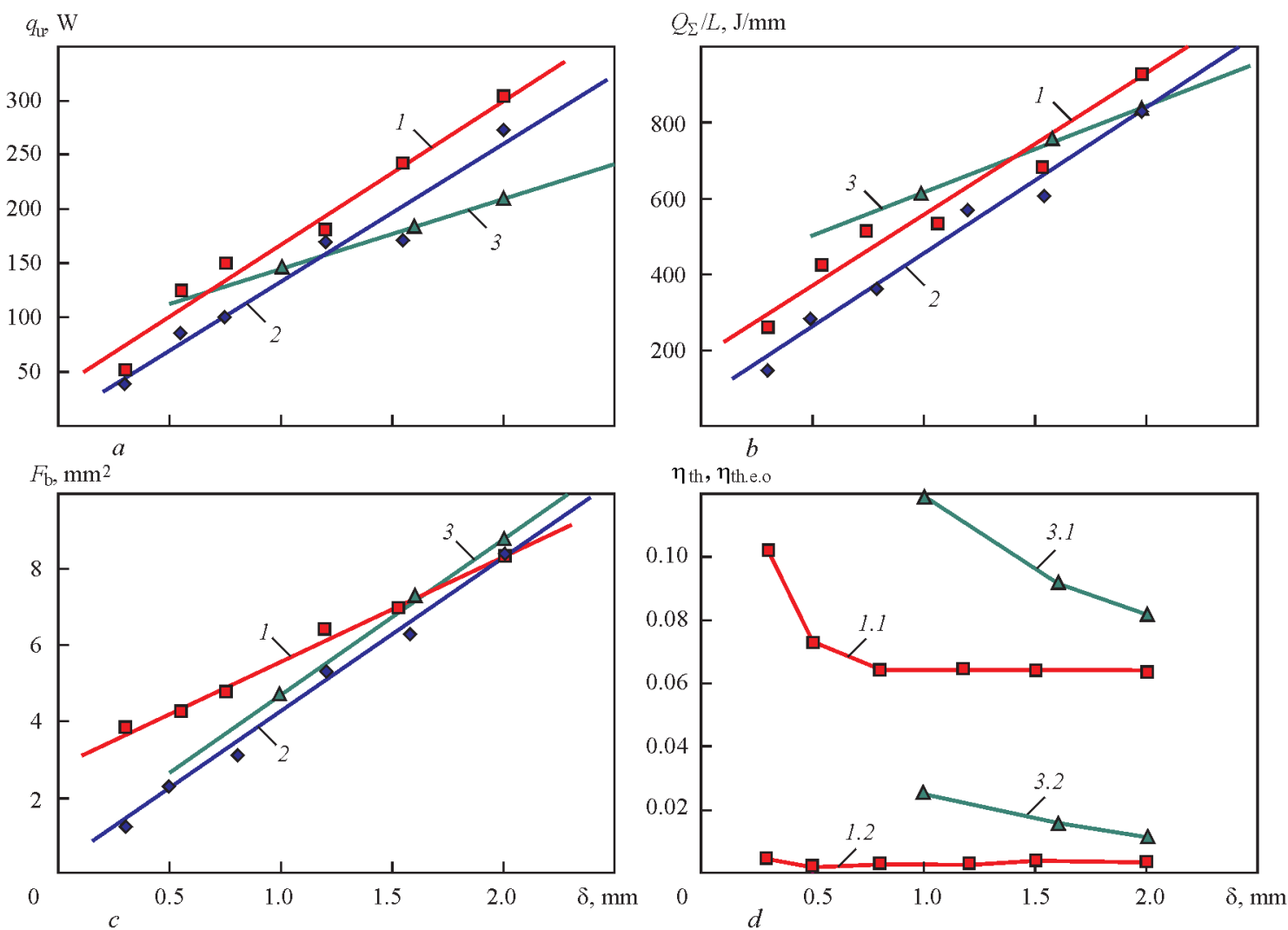

Figure 2. Effect of narrow substrate width $\delta$ on effective heat power of microplasma arc $q_{u}(a)$, heat input $Q_{\Sigma} / L(b)$, cross-section area of deposited bead $F_{\mathrm{b}}(c)$ and thermal efficiency $\eta_{\mathrm{th}}(d): 1$ — surfacing of ZhS32 alloy, Starweld $190 \mathrm{H}$ unit, continuous wire feed, shielding gas Ar; 1.1 - complete thermal efficiency $\eta_{\text {th }}$ of process; 1.2 - component of thermal efficiency used for base metal melting; 2 surfacing of V3K alloy, Starweld 190H unit, continuous powder feed, shielding gas Ar; 3 — surfacing of ZhS32 alloy, UPNS-304M2/ M3 unit, dosed wire feed, shielding gas $95 \% \mathrm{Ar}+5 \% \mathrm{H}_{2} ; 3.1$ - complete thermal efficiency $\eta_{\mathrm{th}}$ of process; 3.2 — component of heat efficiency used for base metal melting

put of the process makes $100-1000 \mathrm{~J} / \mathrm{mm}$, surfacing efficiency is $0.3-1.3 \mathrm{~g} / \mathrm{min}$; bead cross-section area makes $1-9 \mathrm{~mm}^{2} . q_{\mathrm{u}}(\delta), Q_{\Sigma} / L(\delta)$ and $F_{\mathrm{b}}(\delta)$ dependencies are close to linear. Obtained data indicated the specific effect on the process energy indices of filler composition (ZhS32, V3K) and method of disperse wire feed (continuous, dosed), that allows expanding a notion on known methods of process regulation of heat input in the part (welding current, level of plasma arc constriction, reasonable selection of shielding gas composition [1, 4]). Indicated process factors in $q_{\mathrm{u}}<150 \mathrm{~W}$ and $\delta<1.2 \mathrm{~mm}$ range also influences the reduction of deposited bead cross-section. A com- plete thermal efficiency of the process of surfacing on narrow substrate $\delta=0.3-0.2 \mathrm{~mm}$, as a rule, does not exceed $\eta_{\text {th.e }}=6-10 \%$, besides, part of the effective power $q_{\mathrm{u}}$, being spent for melting of base metal, makes $\eta_{\text {th.e. }}=0.16-2.5 \%$. Fraction of the base metal in the deposited one is limited in 5-15\% range, that corresponds with the optimum modes of plasma-powder surfacing [1].

A set range of values of bead shape coefficient $B / H$ in 0.77-1.22 limits (see Table 1 ) allowed specifying technologically possible schemes of shaping of deposited bead [14] varying a series of process factors of microplasma powder surfacing: width of

Table 1. Effect of width of narrow substrate $\delta$ on portion of base metal $\gamma_{\mathrm{b}}$, surfacing efficiency $M_{\mathrm{s}}$ and coefficient of bead shape $B / H$ in microplasma powder surfacing of alloys ZhS32 and V3K

\begin{tabular}{|c|c|c|c|c|c|c|c|c|c|}
\hline \multirow{2}{*}{$\delta, \mathrm{mm}$} & \multicolumn{3}{|c|}{$\gamma_{\mathrm{b}}, \%$} & \multicolumn{3}{c|}{$B / H$} & \multicolumn{3}{c|}{$M_{\mathrm{s}}, \mathrm{g} / \mathrm{min}$} \\
\cline { 2 - 12 } & ZhS32 (c) & ZhS32 (d) & V3K (c) & ZhS32 (c) & ZhS32 (d) & V3K (c) & ZhS32 (c) & ZhS32 (d) & V3K (c) \\
\hline 0.3 & 9.97 & - & 9.26 & 0.787 & - & 1.054 & 0.351 & - & 0.157 \\
\hline 0.55 & 5.11 & - & 5.04 & 0.772 & - & 1.041 & 0.645 & - & 0.333 \\
\hline 0.75 & 8.98 & - & 8.5 & 0.857 & - & 0.930 & 0.639 & - & 0.366 \\
\hline 1.0 & - & 14.16 & & - & 1.201 & - & - & 1.043 & - \\
\hline 1.2 & 11.46 & - & 13.55 & 0.933 & - & 0.936 & 0.826 & - & 0.534 \\
\hline 1.55 & 12.11 & 13.37 & 15.39 & 1.216 & 1.113 & 1.000 & 1.013 & 0.872 & 0.711 \\
\hline 2.0 & 11.19 & 10.64 & 10.31 & 1.032 & 1.206 & 0.969 & 1.276 & 0.958 & 1.261 \\
\hline
\end{tabular}



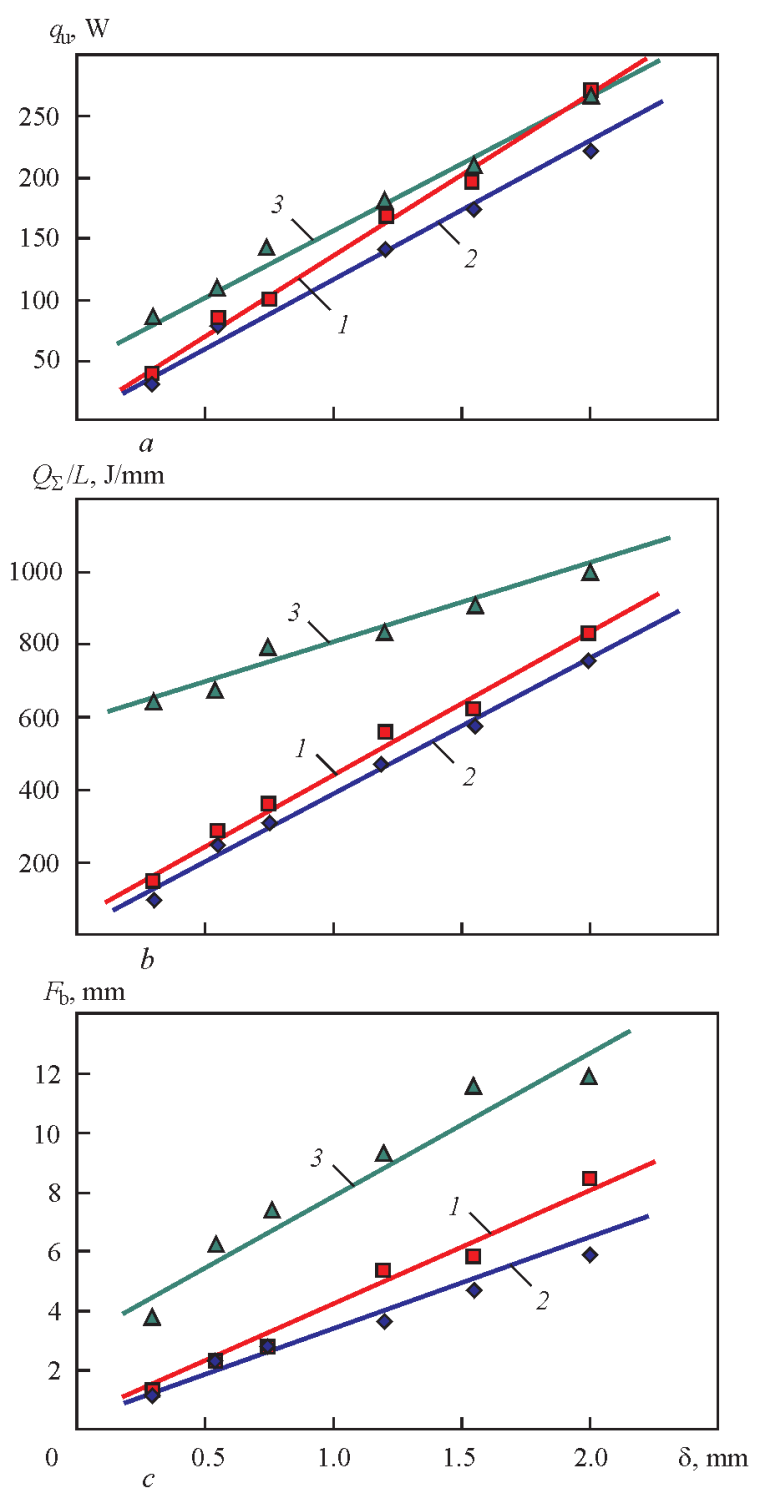

Figure 3. Effect of width of narrow substrate $\delta$ on effective heat power of microplasma arc $q_{\Perp}(a)$, heat input $Q_{\Sigma} / L(b)$, cross-section area of deposited bead $F_{\mathrm{b}}(c)$. Surfacing of V3K alloy, shielding gas Ar, Starweld $190 \mathrm{H}$ unit, continuous powder feed: 1 - direct; 2, 3 - pulse welding current

narrow substrate; effective heat power of arc and efficiency.

$\delta=0.3-2.0 \mathrm{~mm}$ depending on toughness of weld pool molten metal (i.e. deposited metal, since $\left.\gamma_{0} \rightarrow \min \right)$ is characterized by the following changes of shape of deposited beads cross-section:
- at increased toughness (alloy ZhS32) - under the law of increasing ellipse with $H>B$ at $\delta<0.8 \mathrm{~mm}$ and $B>H$ at $\delta>1.5 \mathrm{~mm}$;

- at increased fluidity (alloy $\mathrm{V} 3 \mathrm{~K}$ ) - under the law of increasing circle with $H \approx B$.

Considered above methods of process effect on shape and dimensions of bead being deposited on narrow substrate shall be referred to passive ones, since they can be selected only before surfacing. It is known fact $[1,4]$ that welding current is the process parameter of constricted arc, first of all determining its effective heat power. Respectively, it can have sufficiently easy technological regulation in process of repair surfacing, in particular, at change of width of narrow substrate at local repair of complex geometry blades [4-8]. Therefore, this work also studied the possibility of regulation of bead shape due to application of pulse welding current with different relative pulse duration $S$.

In parallel the investigations were carried out for disperse filler materials V3K (STARWELD 190H unit, $S \approx 1.5$ ) and ZhS32 (UPNS304M2/M3 unit, $S \approx 4.5$ ). Additionally, 2 types of pulse modes were considered, except surfacing with direct welding current (mode 1):

mode 2: $I_{\text {pul }}<I_{\mathrm{b}}, I_{\mathrm{p}}<I_{\mathrm{b}}$;

mode 3: $I_{\text {pul }}^{\text {pul }}>I_{\mathrm{b}}, I_{\mathrm{p}}<I_{\mathrm{b}}$.

where $I_{\mathrm{b}}$ is the basic value of direct welding current; $I_{\text {pul }}, I_{\mathrm{p}}$ are the values of welding current at pulse and pause, respectively.

The dependencies of change of energy parameters of the process of microplasma powder surfacing and bead shape for narrow substrate $\delta=0.3-2.0 \mathrm{~mm}$ are presented in Figure 3, Table 2 and Figure 4, Table 3 for conditions of surfacing of V3K and ZhS32 alloys, respectively. Different position of dependencies $q_{\mathrm{u}}(\delta)$, $Q_{\Sigma} / L(\delta)$ and $F_{\mathrm{b}}(\delta)$ relatively to similar ones in direct current surfacing (see Figures 3, 4) is noted at mode 3 depending on value of relative pulse duration of welding current in surfacing on narrow substrate $\delta \leq 2 \mathrm{~mm}$.

Obtained results indicate the possibility of efficient regulation of the dimensions of cross-section of bead being deposited on narrow substrate, due to reasonable selection of parameters of pulse welding current. Also, pulse current surfacing of V3K alloy promotes for somewhat reduction (per 2-5\%) of base metal

Table 2. Effect of width of narrow substrate $\delta$ on portion of base metal $\gamma_{b}$, surfacing efficiency $M_{\mathrm{s}}$ and coefficient of bead shape $B / H$ in microplasma powder surfacing of alloy V3K using continuous (mode 1) and pulse current (modes 2 and 3 )

\begin{tabular}{|c|c|c|c|c|c|c|c|c|c|}
\hline \multirow{2}{*}{$\delta, \mathrm{mm}$} & \multicolumn{3}{|c|}{$\gamma_{\mathrm{b}}, \%$} & \multicolumn{3}{c|}{$M_{\mathrm{s}}, \mathrm{g} / \mathrm{min}$} & \multicolumn{3}{c|}{$B / H$} \\
\cline { 2 - 11 } & Mode 1 & Mode 2 & Mode 3 & Mode 1 & Mode 2 & Mode 3 & Mode 1 & Mode 2 & Mode 3 \\
\hline 0.3 & 9.26 & 7.47 & 4.73 & 0.157 & 0.116 & 0.251 & 1.05 & 0.71 & 0.72 \\
\hline 0.55 & 5.04 & 7.31 & 1.67 & 0.333 & 0.287 & 0.332 & 1.04 & 0.90 & 0.85 \\
\hline 0.75 & 8.50 & 13.37 & 4.64 & 0.366 & 0.329 & 0.456 & 0.93 & 1.06 & 0.74 \\
\hline 1.2 & 13.55 & 14.12 & 8.20 & 0.534 & 0.485 & 0.785 & 0.94 & 0.92 & 0.83 \\
\hline 1.55 & 15.39 & 8.47 & 6.48 & 0.711 & 0.616 & 1.042 & 1.00 & 0.92 & 0.79 \\
\hline 2.0 & 10.31 & 11.32 & 6.74 & 1.260 & 0.678 & 1.496 & 0.97 & 1.16 & 0.80 \\
\hline
\end{tabular}



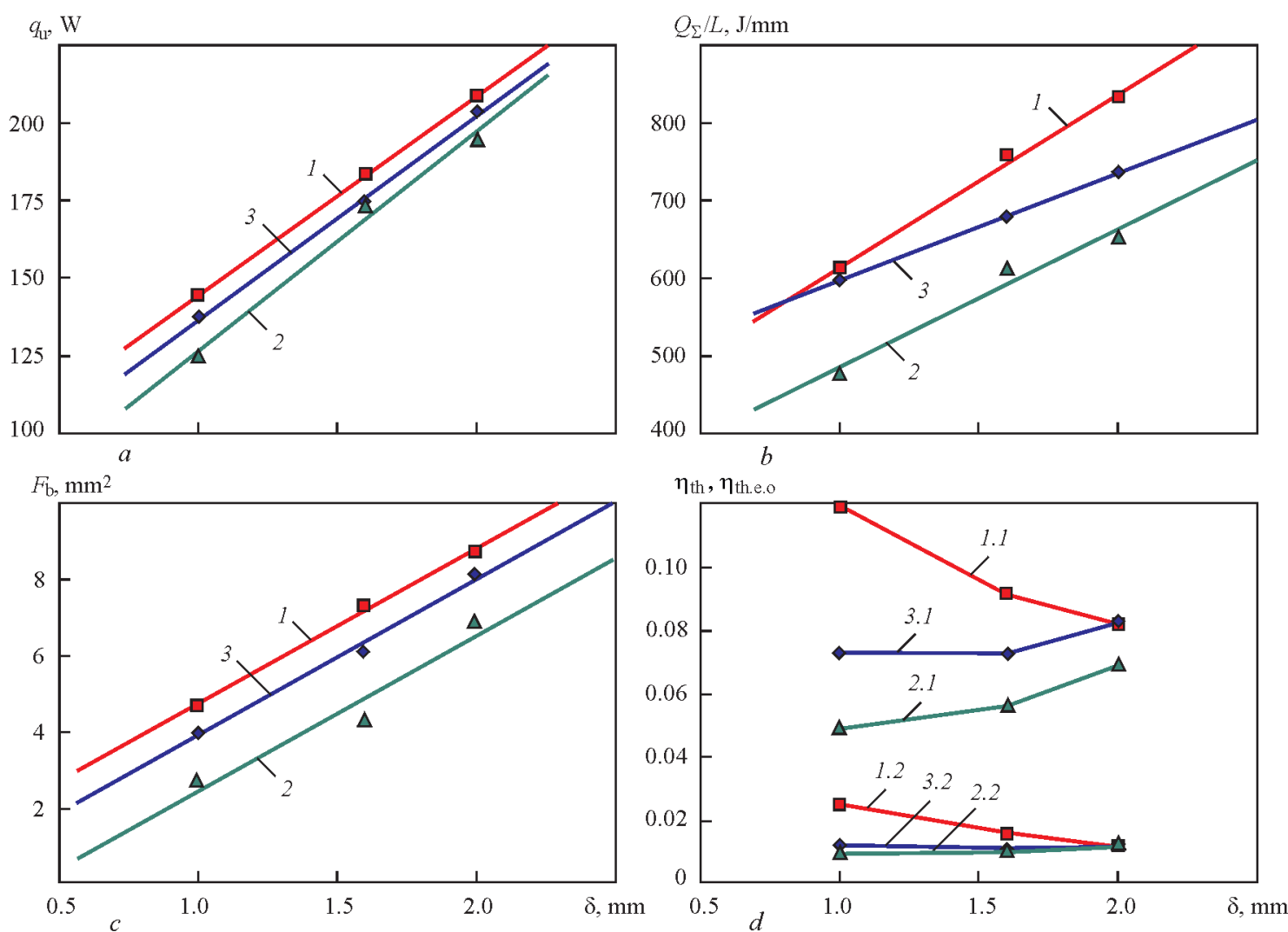

Figure 4. Effect of width of narrow substrate $\delta$ on effective heat power of microplasma arc $q_{\mathrm{u}}(a)$, heat input $Q_{\Sigma} / L$, cross-section area of deposited bead $F_{\mathrm{b}}(c)$ and thermal efficiency $\eta_{\mathrm{th}}(d)$ in variation of narrow substrate width $\delta$. Surfacing of ZhS32 alloy, shielding gas $95 \% \mathrm{Ar}+5 \% \mathrm{H}_{2}$, UPNS-304M2/M3 unit, dosed powder feed: 1 — direct welding current; 2 , 3 — pulse welding current (modes 2 and 3); 1.1, 2.1, 3.1 - complete thermal efficiency $\eta_{\text {th }}$ of process; 1.2, 2.2, 3.2 - component of thermal efficiency $\eta_{\text {th.e.o }}$ used for base metal

fraction in comparison with direct current surfacing (see Table 2). It becomes possible to shape deposited bead under increasing ellipse law with $H>B$ for all range of width of narrow substrate $\delta=0.3-2.0 \mathrm{~mm}$. Possibilities of decrease of base metal fraction and regulation of bead shape coefficient due to application of pulse modes is somewhat limited (see Table 3) in pulse current surfacing of ZhS32 alloy.

The investigations of effect of rate of microplasma powder surfacing of ZhS32 and V3K alloys on energy indices of the process and bead cross-section area were carried out in a mode of automatic direct current surfacing using robotic unit 190HP. It is determined (Figure 5) that increase of rate of surfacing on $\delta=0.3-3.0 \mathrm{~mm}$ width narrow substrate from 1.2 to $3.6 \mathrm{~m} / \mathrm{h}$ promotes for on average 3 times reduction of cross-section area of the deposited bead $F_{b}$, and 4 times decrease of heat inputs in the part $Q_{\Sigma} / L$. The productivity of surfacing on $\delta=3.0 \mathrm{~mm}$ narrow sub- strate in the considered rate range on data of Figure 5 makes approximately $3 \mathrm{~g} / \mathrm{min}$ and reaches the powder feed productivity.

It is additionally shown (see Table 4) that application of disperse filler in microplasma surfacing is more preferable in comparison with filler from microwire, since allows reducing the effective heat power of arc more than 2 times, decreasing 1.8 time heat input, and rising 1.8 time surfacing efficiency. Also, following from work [15], reduction of heat input to laser-powder surfacing level in microplasma powder surfacing is possible with rise of its rate approximately to $22.6 \mathrm{~m} / \mathrm{h}$.

Evaluation of common and separate effect of the process factors of microplasma arc effective heat power and heat input on bead cross-section shape was carried out by means of analysis of goal functions [18] $\varepsilon_{q_{u}}, \varepsilon_{Q_{\Sigma} / L}$, and $\varepsilon_{F}$ in form of relationship of effective heat power of microplasma arc, heat input and

Table 3. Effect of width of narrow substrate $\delta$ on portion of base metal $\gamma_{b}$, surfacing efficiency $M_{\mathrm{s}}$ and coefficient of bead shape $B / H$ in microplasma powder surfacing of alloy ZhS32 using direct (mode 1) and pulse current (modes 2 and 3 )

\begin{tabular}{|c|c|c|c|c|c|c|c|c|c|}
\hline \multirow{2}{*}{$\delta, \mathrm{mm}$} & \multicolumn{3}{|c|}{$\gamma_{\mathrm{b}}, \%$} & \multicolumn{3}{c|}{$M_{\mathrm{s}}, \mathrm{g} / \mathrm{min}$} & \multicolumn{3}{c|}{$B / H$} \\
\cline { 2 - 10 } & Mode 1 & Mode 2 & Mode 3 & Mode 1 & Mode 2 & Mode 3 & Mode 1 & Mode 2 & Mode 3 \\
\hline 1.0 & 17.17 & 15.09 & 11.57 & 0.950 & 0.344 & 0.585 & 1.04 & 0.89 & 0.79 \\
\hline 1.55 & 12.61 & 15.9 & 13.64 & 0.970 & 0.557 & 0.750 & 1.11 & 1.07 & 1.22 \\
\hline 2.0 & 10.63 & 13.7 & 11.08 & 1.020 & 0.773 & 1.004 & 1.21 & 1.11 & 1.07 \\
\hline
\end{tabular}



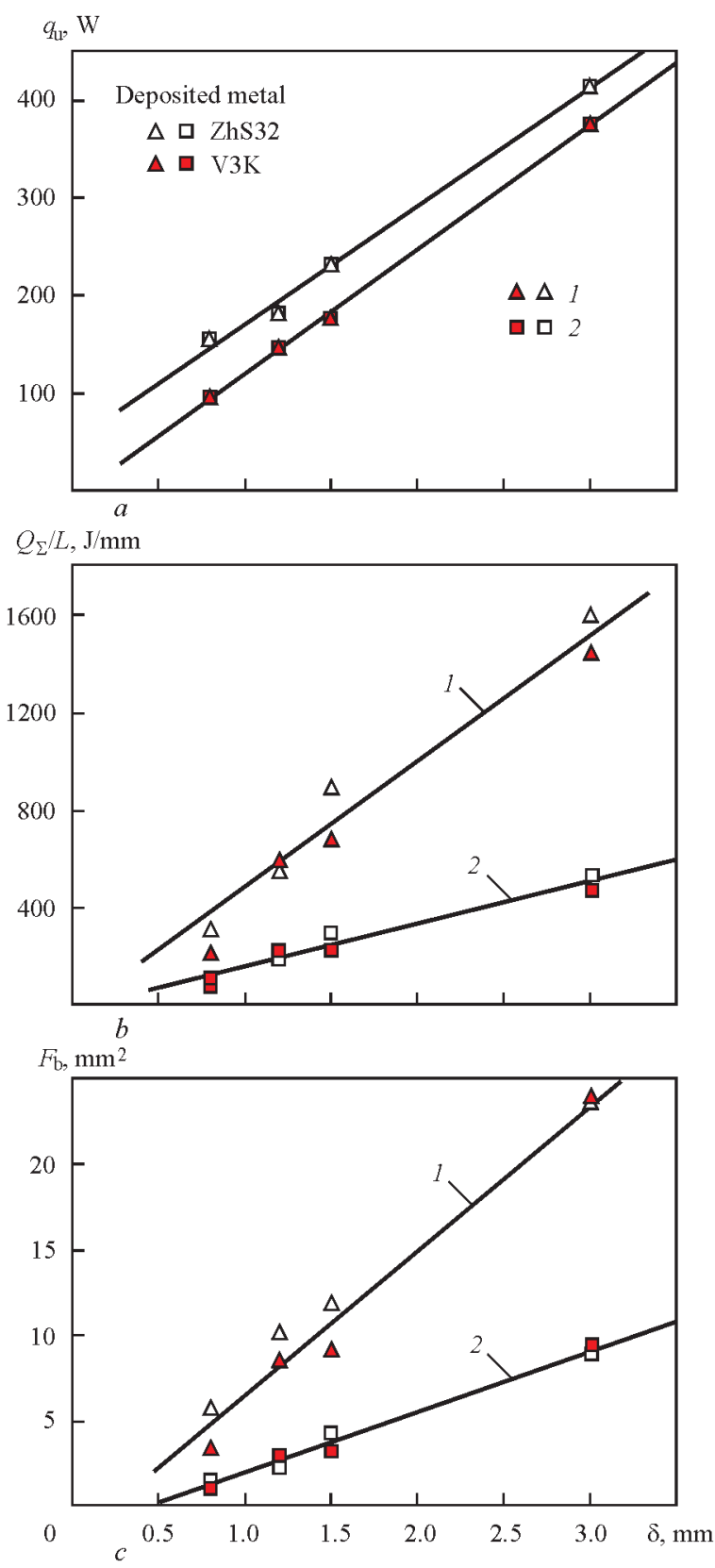

Figure 5. Effect of width of narrow substrate $\delta$ and average surfacing rate on effective heat power of microplasma $\operatorname{arc} q_{u}(a)$, heat input $Q_{\Sigma} / L(b)$, cross-section area of deposited bead $F_{\mathrm{b}}(c): 1$ $1.2 ; 2-3.6 \mathrm{~m} / \mathrm{h}$. Robotic unit Starweld $190 \mathrm{H}$, continuous powder feed, shielding gas $\mathrm{Ar}$

cross-section areas of the deposited bead at current and basic modes of surfacing, respectively. The basic mode was, as a rule, a direct current surfacing mode. The values of goal function $\varepsilon_{F}$ were evaluated at varying process factors in form of different modes of pulse welding current $\left(I_{\text {pul }}<I_{\mathrm{b}}, I_{\mathrm{p}}<I_{\mathrm{b}}\right.$ and $\left.I_{\text {pul }}>I_{\mathrm{b}}, I_{\mathrm{p}}<I_{\mathrm{b}}\right)$ and surfacing rate, which were considered through the indices of effective heat power of microplasma arc and heat input. The regression dependencies of change of goal functions $\varepsilon_{F}=f\left(\varepsilon_{q_{u}}\right)$ and $\varepsilon_{F}=f\left(\varepsilon_{q_{u}}, \varepsilon_{Q_{\Sigma} / L}\right)$, relatively to their basic level $\left(\varepsilon_{q_{u}}=1, \varepsilon_{Q_{\Sigma} / L}=1, \varepsilon_{F}=1\right)$ are presented in form of $2 \mathrm{D}$ and $3 \mathrm{D}$ (contour) plots in Figures 6 and 7.
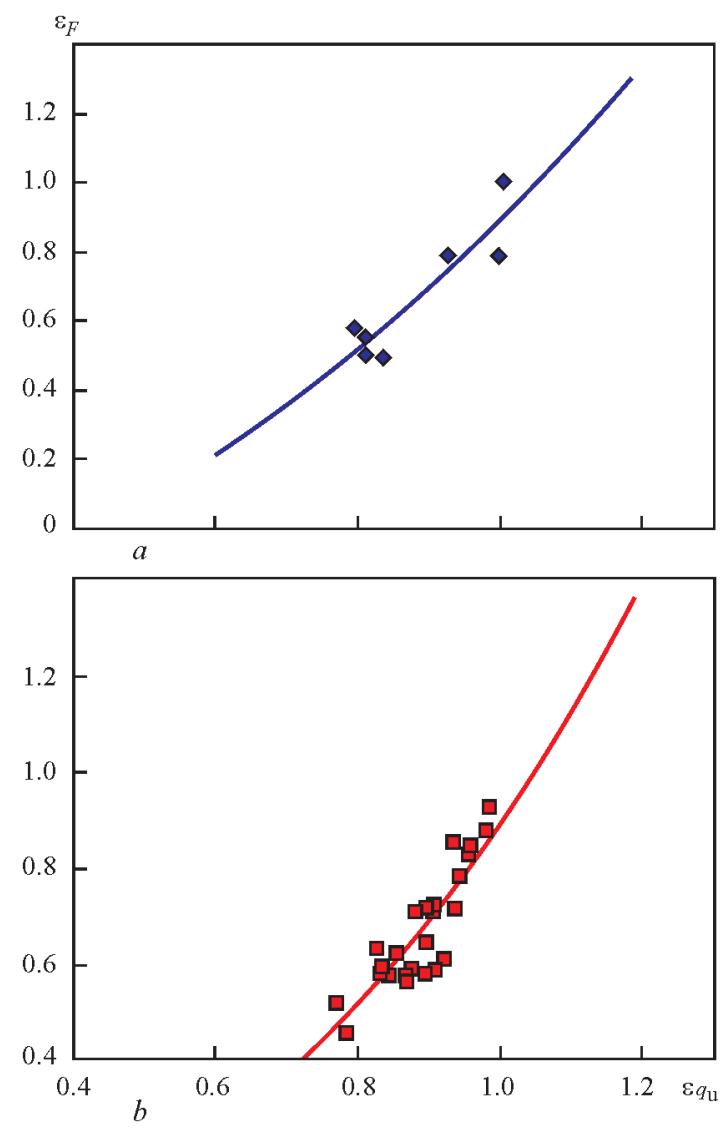

Figure 6. Dependence of relative cross-section area of deposited bead $\varepsilon_{F}$ on relative effective heat power of microplasma arc $\varepsilon_{q_{u}}$ in microplasma powder surfacing on narrow substrate: $a-$ alloy V3K, unit Starweld $190 \mathrm{H}$, continuous powder feed, shielding gas $\mathrm{Ar}, \delta=0.3-3.0 \mathrm{~mm} ; b-$ unit UPNS-304M2/M3, dosed powder feed, shielding gas $95 \% \mathrm{Ar}+5 \% \mathrm{H}_{2}, \delta=1.0-2.0 \mathrm{~mm}$

It is determined that $20 \%$ reduction of effective heat power of microplasma arc promotes for $30-50 \%$ decrease of cross-section area of the deposited bead for V3K and ZhS32 alloys, respectively. At that, the relationship of width B to height of deposited bead $H$ for pulse welding current lies, as a rule, in 0.7-0.92 ranges.

Change of surfacing heat input (mainly due to its rate), in particular in combination with some increase of effective heat power of microplasma arc, has more significant effect on shape of the bead, deposited on narrow substrate (see Figures 6 and 7). 2-3 times increase of heat input in surfacing with continuous feed of powder allows receiving the same rise of bead cross-section area, and up to 3.6 times growth in combination with simultaneous increase of effective heat power of microplasma arc by $70 \%$ (see Figure 7, $a$ ). In surfacing with dosed powder feed, 2.5 times increase of heat input allows rising cross-section area of the deposited bead up to 3.5 times and to 5.5-6 times (see Figure 7, $b$ ) in combination with simultaneous increase of effective heat power of microplasma arc by 10-30 \%.

Simultaneous reduction of effective power of the microplasma arc and heat input per $20-30 \%$ relative- 
Table 4. Comparison of characteristics of bead cross-section $\left(B, H, \gamma_{\mathrm{b}}\right)$, effective power of part heating $q_{\mathrm{u}}$, heat input $Q_{\Sigma} / L$ and surfacing efficiency $M_{\mathrm{s}}$ in microplasma and laser surfacing

\begin{tabular}{|c|c|c|c|c|c|c|c|c|}
\hline $\begin{array}{l}\text { Surfacing } \\
\text { process }\end{array}$ & Deposited metal & $B, \mathrm{~mm}$ & $H, \mathrm{~mm}$ & $q_{\mathrm{u}}, \mathrm{W}$ & $\gamma_{b}, \%$ & $\begin{array}{l}Q_{\Sigma} / L \\
\mathrm{~J} / \mathrm{mm}\end{array}$ & $\begin{array}{l}M_{\mathrm{s}}, \\
\mathrm{g} / \mathrm{min}\end{array}$ & Source \\
\hline $\begin{array}{l}\text { Microplasma, } \\
\approx 22.6 \mathrm{~m} / \mathrm{h}\end{array}$ & Powder H13 tool steel & 2.0 & 0.2 & $\approx 280^{* 1}$ & - & $\approx 45^{* 1}$ & 1.0 & Wang H. et al. (2003). [15] $]^{* 3}$ \\
\hline \multirow{2}{*}{$\begin{array}{l}\text { Microplasma, } \\
\approx 3.6 \mathrm{~m} / \mathrm{h}\end{array}$} & Wire AISI P20 Ø 0.3 mm & $1.9 \pm 0.06$ & $0.9 \pm 0.04$ & 400 & $5.12 \pm 0.12$ & 380.95 & 0.47 & Jhavar S. et al. (2014). [16 $]^{* 3}$ \\
\hline & Powder V3K, 53...-160 $\mu \mathrm{m}$ & 2.0 & 1.8 & $\approx 15$ & 211.7 & 0.87 & 1.87 & This work $^{* 2}$ \\
\hline $\begin{array}{l}\text { Yb:YAG Laser } \\
\approx 24 \mathrm{~m} / \mathrm{h}\end{array}$ & Powder Ti-6Al-4V & $1.9-2.1$ & $0.15-0.22$ & 400 & - & 48 & 1.0 & Gharbi et al. (2012). [17] ${ }^{* 3}$ \\
\hline
\end{tabular}
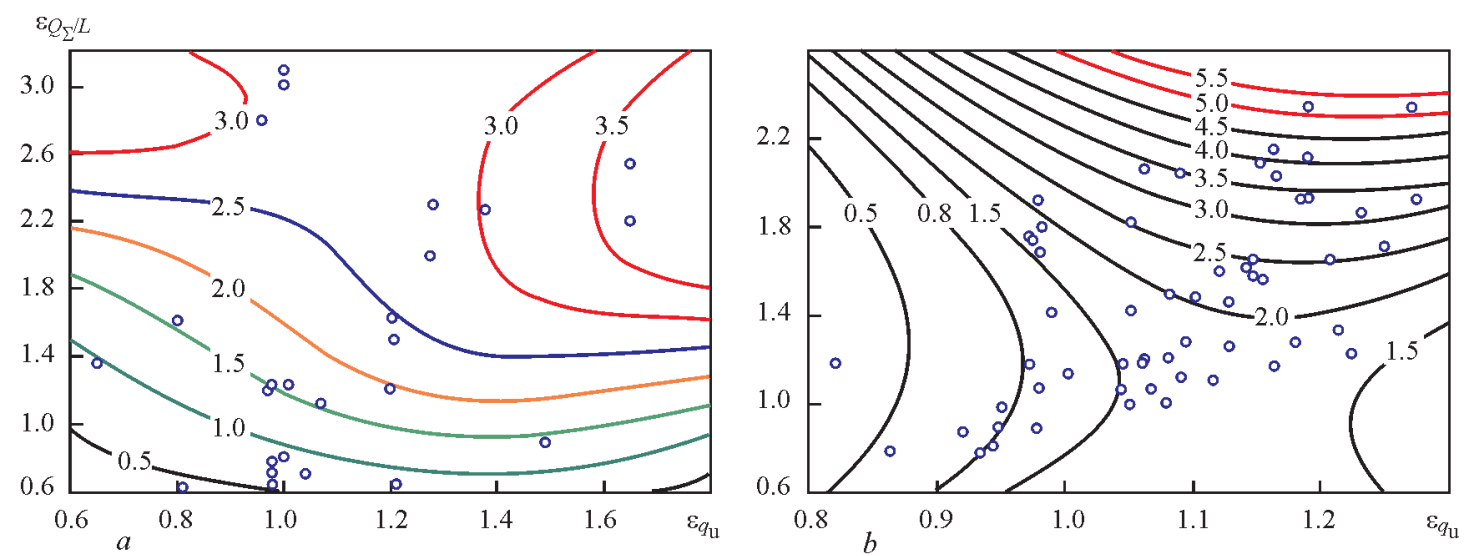

Figure 7. Contour diagram of change of relative area of deposited bead cross-section $\varepsilon_{F}$ on relative effective heat power of microplasma arc $\varepsilon_{q_{u}}$ and relative heat input of microplasma surfacing $\varepsilon_{Q_{\Sigma} / L}: a-$ V3K alloy, unit Starweld 190H, continuous powder feed, shielding gas $\mathrm{Ar}, \delta-0.3-3.0 \mathrm{~mm} ; b-\mathrm{UPNS}-304 \mathrm{M} 2 / \mathrm{M} 3$ unit, dosed powder feed, shielding gas $95 \% \mathrm{Ar}+5 \% \mathrm{H}_{2}, \delta=1.0-2.0 \mathrm{~mm}$

ly to the basic level of $\varepsilon_{q_{u}}, \varepsilon_{Q_{\Sigma} / L}$ values allows 1.5-2.0 times decrease of bead cross-section (see Figure 7).

Analysis of experimental data, given in Figures $2-7$, allowed outlining 3 basic laws of change of cross-section of the bead deposited on narrow substrate of $\delta=0.5-3.0 \mathrm{~mm}$ width. First of them is caused by variation of width of narrow substrate (Figure $8, a$ ) at continuous rate of surfacing: its 6 times extension promotes for 4-8 times increase of effective heat power of the microplasma arc necessary for surfacing, that is accompanied by 8-12 times rise of bead cross-section area. The second is caused by change of effective heat power of microplasma arc per $\pm 20 \%$ at constant width of narrow substrate and surfacing rate (Figure $8, b$ ), that is accompanies by 1.3-2.0 times change of bead cross-section area. The third is promoted by 3-4 times variation of surfacing heat input due to its rate at constant width of narrow substrate and effective heat power of microplasma arc (Figure $8, c$ ), that is accompanied by 3-4 times corresponding changes of bead cross-section area. Present laws of change of bead cross-section, as a rule, simultaneously match on practice to that or another degree.
It was assumed earlier in argon-arc welding [2, 3 , 10] that the process strength in welding of high-temperature nickel alloys with high content of strengthening $\gamma^{\prime}$-phase is determined with a condition of extreme limitation of welding current and base metal penetration depth. Experience of application of the microplasma powder surfacing [4-8] indicates that the pro-
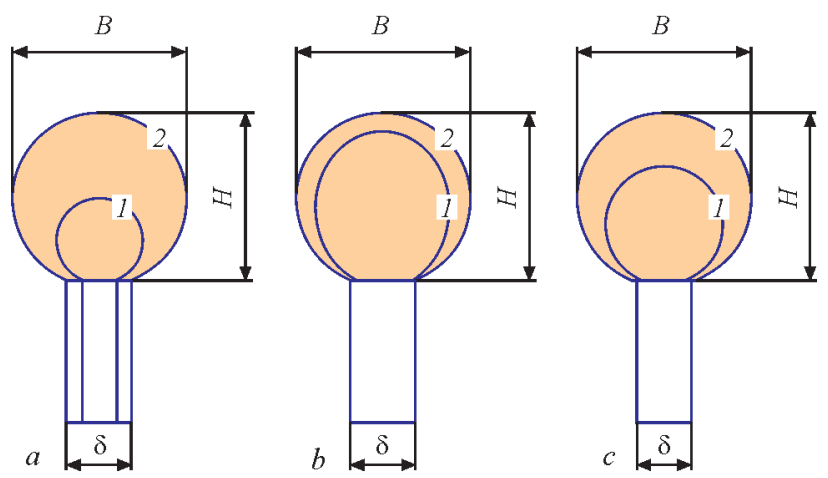

Base metal

Deposited metal

Figure 8. Basic dependencies of change of bead cross-section shape in surfacing on narrow substrate depending on: width of narrow substrate $(a)$, varying effective heat power of microplasma arc (b), changing heat input $(c) ; 1 \rightarrow 2-$ direction of bead cross-section change 
cess strength in single-layer surfacing of blade edges can be provided in sufficiently wide range of mode parameters $\left(I=2-35 \mathrm{~A}, v=0.2-5.0 \mathrm{~m} / \mathrm{h}, F_{\mathrm{b}}<30\right.$ $35 \mathrm{~mm}^{2}$ ), where the base metal penetration depth, as a rule, does not exceed $1 \mathrm{~mm}$.

Analysis of corresponding modes of surfacing on narrow substrate $\delta \leq 3 \mathrm{~mm}$, which are supposed to be close to optimum, showed that 2-4 times change of cross-section area of a bead being deposited promotes for insignificant variation of portion of base metal in the deposited one and it does not exceed $15 \%$. Respectively, portion of heat consumed for base metal melting does not exceed $2.5 \%$ of effective heat power of the microplasma arc. Therefore, it is relevant to formulate additional criteria of the process strength at transfer to multi-layer surfacing of the blade edges.

A surfacing heat input can be such an additional criterion of the process strength based on stated in works $[11,14]$ relationship of tendency to crack formation for considered welded joints and total heat input in the part as well as stated in this work dependencies of regulation of cross-section of the deposited bead. Thus, cross-section area of the deposited layer in multi-layer surfacing shall be selected taking into account heat input for determination of narrow substrate width.

\section{Conclusions}

1. Process range of energy indices was specified for single-layer microplasma powder surfacing on narrow substrate of width less than $3 \mathrm{~mm}$. In keeping with other technological recommendations, it is possible to provide the process strength of welded joint «base-deposited metal», in which at least one of the materials is high-temperature nickel alloy containing more than 55 vol.\% of $\gamma^{\prime}$-phase, using 30-420 W effective heat power of microplasma arc; 100-1600 J/ $\mathrm{mm}$ surfacing heat input; $0.3-3.0 \mathrm{~g} / \mathrm{min}$ surfacing efficiency; $1-25 \mathrm{~mm}^{2}$ deposited bead cross-section area.

2. In this case under conditions of limited base metal penetration depth, the process regulation of shape and size of cross-section of deposited bead can be done by means of change of effective heat power of the microplasma arc, surfacing heat input, reasonable selection of deposited metal composition and powder feed method (dosed, continuous).The most efficient among them at constant width of narrow substrate are 2.5-4 times variation of heat input, 30-50 \% change of effective heat power of the microplasma arc as well as 3.5-6 times variation at their combination. Detected dependencies of the bead shape regulation are used at JSC «Motor Sich» under conditions of serial repair of GTE blades.

3. Additional criteria of the process strength in repair multi-layer microplasma powder surfacing of blade edges of high-temperature nickel alloys can be the value of heat input and related with it height and cross-section area of the deposited metal layer.

1. Gladky, P.V., Pereplyotchikov, E.F., Ryabtsev, I.A. (2007) Plasma surfacing. Kiev: Ekotekhnologiya.

2. Peremilovsky, I.A., Gejchenko, V.S., Frumin, I.I. (1976) Surfacing repair of turbine blades of aircraft engines. Avtomatich. Svarka, 5, 54-56.

3. Petrik, I.A., Peremilovsky, I.A. (2001) Further development of technology for hardening of flange platform faces of turbine blades from high-temperature alloys. Tekhnologicheskie Sistemy, 3, 90-92.

4. Yarovytsyn, O.V. (2009) Microplasma powder surfacing of high-temperature nickel alloys containing 45-65\% of $\gamma^{\prime}$-phase: Syn. of Thesis for Cand. of Techn. Sci. Degree. Kiev: PWI.

5. (2010) Technological Seminar Deloro Stellite in Zaporozhie. The Paton Welding J., 1, 46-49.

6. Yushchenko, K.A., Savchenko, V.S., Yarovitsyn, A.V. et al. (2010) Development of the technology for repair microplasma powder cladding of flange platform faces of aircraft engine high-pressure turbine blades. Ibid., 8, 21-24.

7. Yushchenko, K.A., Yarovitsyn, A.V. (2012) Improvement of technology of repair of upper flange platform faces of aircraft engine blades. In: Complex Program of NASU on Problems of Service Life and Service Safety of Constructions, Structures and Machines. Transact. on Results of 2010-2012. Kiev: PWI.

8. Zhemanyuk, P.D., Petrik, I.A., Chigilejchik, S.L. (2015) Experience of introduction of the technology of reconditioning microplasma powder surfacing at repair of high-pressure turbine blades in batch production. The Paton Welding J., 8, 39-42.

9. Boguslaev, V.A., Muravchenko, V.M., Zhemanyuk, P.D. et al. (2003) Technological support of service characteristics of gas turbine engine parts. Turbine blades. Pt 2. Zaporozhie: JSC Motor Sich.

10. Sorokin, L.I., Lukin, V.I., Bagdasarov, Yu.S. (1997) Weldability of cast high-temperature alloys of ZhS6 type. Svarochn. Proizvodstvo, 6, 12-17.

11. Yarovitsyn, A.V. (2015) Energy approach in analysis of microplasma powder surfacing modes. The Paton Welding J., 5/6, 22-25.

12. Popov, S.A. (1987) Grinding operations. Moscow: Vysshaya Shkola.

13. Kondratyuk, E.V., Leontiev, V.A., Shusha, A.V. et al. (2013) Profile deep grinding of gas turbine engine parts. Promyshlennost $v$ Fokuse, 5, 22-24.

14. Yushchenko, K.A., Yarovitsyn, A.V., Khrushchov, G.D. et al. (2015) Analysis of process of bead shaping in cladding on narrow substrate. The Paton Welding J., 9, 20-27.

15. Wang, H., Jiang, W., Vallant, M. et al. (2003) Microplasma powder deposition as a new solid freeform fabrication process. Proc. Inst. Mech. Engrs., 217(Pt B.J.), 1641-1650.

16. Suyog Jhavar, Jain, N.K., Paul, C.P. (2014) Development of microplasma transferred arc ( $\mu$-PTA) wire deposition process for additive layer manufacturing applications. J. of Materials Processing Technology, 214(5), 1102-1110.

17. Gharbi, M., Peyre P., Gorny, C. et al. (2012) Influence of various process conditions on surface finishes induced by direct metal deposition laser technique on a Ti-6Al-4V alloy. Ibid., 213(5), 791-800.

18. (1988) Mathematical dictionary. Ed. by Yu.V. Prokhorov. Moscow: Sovremennaya Encyclopediya.

Received 06.07.2016 